\title{
Multi-Stage Filtration (MSF) Technology with Natural Coagulants for Raw Water Treatment from the Sinu River in Colombia
}

\author{
Jhon Jairo Feria Díaz*, Fernando Jove Wilches and Rodrigo Hernandez Ávila \\ Department of Civil Engineering, University of Sucre, Carrera 28 No. 5-267, Puerta Roja, \\ Sincelejo, Colombia; jhon.feria@unisucre.edu.co,fejowi@yahoo.es, \\ rodrigo.hernandez@unisucre.edu.co
}

\begin{abstract}
Objective: To determine turbidity removal efficiency of raw water samples, by using Multi-Stage Filtration technology and complemented with natural coagulants. Methods/Analysis: Water samples were taken from the Sinu River. A pilot plant was set up in laboratory, and treatability tests were carried out on samples with different scenarios. Findings: The best treatment for raw water was obtained when $240 \mathrm{~m}^{3} \mathrm{~m}^{-2} \mathrm{~d}^{-1}$ rates were applied for $200 \mathrm{NTU}$ initial turbidity. There were no alterations in $\mathrm{pH}$ and water alkalinity after treatability tests. Application: This raw water treatment technology is very useful and appropriate to be applied in rural areas with difficult access and scarce economic resources, since its simplicity does not require costly inputs or maintenance.
\end{abstract}

Keywords: Activated Carbon, Moringa oleifera, Multi-Stage Filtration, Natural Coagulants, Water Treatment

\section{Introduction}

Quality Risk Index of Water -IRCA 1 is used in Colombia as an indicator to determine water quality, based on degree of risk of diseases occurrence related to non-compliance with physical, chemical and microbiological characteristics of water for human consumption. Generally, in the country, large and medium urban centers receive a supply of decent quality water, without risk or minimal risk to human health and; as urban size decreases and rurality increases; water quality worsens, increasing risk level ${ }^{2}$. In this way, in smaller municipalities and rural areas, IRCA is predominantly high and in some cases sanitarily unviable. In 2016, out of the total of departments that administratively make up the country, $37.5 \%$ presented water with no risk in the urban area and $15.6 \%$ in rural area. In contrast, $31.25 \%$ of the departments had a high-risk level in the rural area ${ }^{3}$.
This situation is mainly due because in rural population centers infrastructure for provision of potable water and basic sanitation, is built without a technical and financial analysis to allow choosing the most appropriate alternative to fit demand features. Therefore, in many cases, the selected alternative requires substantial investments and continuous technical assistance, representing high operation and maintenance costs that communities are not able to pay. Therefore, infrastructure is neither operated nor used ${ }^{4}$.

Multi-Stage Filtration (MSF) can provide a robust treatment alternative for surface water sources of variable quality in rural communities, with low operation and maintenance costs. MSF is a combination of slow sand filters (Slow Sand Filters (SSFs)) and pre-treatment systems. It was developed in the 1990s by researchers in Colombia, where is now being applied on a larger scale. In addition, some efforts are being made to support wider

${ }^{*}$ Author for correspondence 
dissemination and further development, particularly in Latin America 5 . Worldwide experience with MSF shows the significant potential of this treatment concept to produce potable water from contaminated turbid water ${ }^{6}$.

Water Quality obtained using MSF technology is comparable, and even better than the one obtained with a potabilization plant with conventional technology, since MSF elimination processes are mainly physical and biological ${ }^{5}$.

The use of natural coagulants is an important option in water treatment for small communities. They can be prepared manually, allow a considerable reduction in turbidity and apparent color of raw water ${ }^{7}$ and they do not produce significant changes in $\mathrm{pH}$ and alkalinity of treated water $\stackrel{8,9}{\text {. }}$.

Among the most effective and proven natural coagulants is Moringa oleifera seed extract. Its coagulant features have been widely recognized and it is undoubtedly the natural coagulant most studied by the scientific community ${ }^{10}$.

This study aimed at determining the efficiency of MSF technology in raw water treatment clarified with Moringa oleifera seed coagulant and at verifying its technical viability as a purification solution in rural areas.

\section{Material and Methods}

\subsection{Samples of Raw Water}

Water samples for this study were taken from the Sinu River, specifically from the irrigation channel located in the Mocari neighborhood, city of Monteria. Two simple samplings were carried out, the first in the dry season and the second in the rainy season of the region in 2013.

\subsection{Filters Materials and Preparation of Natural Coagulant}

Sand and gravel for the filter train were taken from the Sinu River. It was necessary to carry out washing and sieving processes to achieve the desired quality. For sieving the sand, a $0.7 \mathrm{~mm}$ sieve was used, while for the average gravel a 0.5 "- 2" sieve was used. The 2 "- 4 sieve was used for the gravel ${ }^{11}$.

The coagulant used for this work was obtained from Moringa oleifera seeds following the procedure described by $\underline{12}$. Turbidity, $\mathrm{pH}$ and alkalinity of water were estimated, according to the standard methods proposed by The American Public Health Association ${ }^{13}$.

\subsection{Multi-Stage Filtration Pilot Plant (MSF) Assembly}

Three (3) filters were mounted on 6" PVC pipe, with a length of $75 \mathrm{~cm}$ for each tube. The first tube corresponded to the Coarse Gravel Filter, which stones had a diameter between 2 to 4 in and filled the tube $60 \mathrm{~cm}$. The second tube was the medium gravel coarse filter, with stones diameter between 0.5 to 2 in and filling up to $60 \mathrm{~cm}$. The third Tube was the slow sand filtration unit, made up of a $10 \mathrm{~cm}$ thick gravel base of the tube filling, followed by an average $10 \mathrm{~cm}$ gravel filling and, finally a $20 \mathrm{~cm}$ sand layer. The filters were connected in line, by means of $\emptyset \frac{1}{2}$ "PVC hoses.

\subsection{Filtration Rates}

Hydraulic pre-tests were carried out in the MSF pilot plant to define the best application rates. The flow was calculated by volumetric gauging and filtration rate was determined with the pipe surface area.

\subsection{Experimental Design}

An experimental design $2^{3}$ was made, that is, of 3 factors in two levels. The first factor taken was filtration rates (100 and $160 \mathrm{~m}^{3} \mathrm{~m}^{-2} \mathrm{~d}^{-1}$ ), the second factor was turbidity of raw water of the Sinu River (105 and 208 NTU) and the third factor was coagulant application (clarified water and not clarified water). The variables measured responses were turbidity, $\mathrm{pH}$ and alkalinity of the effluent water of the MSF pilot plant. The Statgraphics Centurion XVI Software (Version 16.0.07) was used to analyze the results and an ANOVA was applied with a 95\% confidence level

\section{Results and Discussion}

Initial characteristics of samples of raw water from the Sinu River, used in the different trials, are shown in Table 1.

Table 1. Characteristics of turbidity, $\mathrm{pH}$ and alkalinity of raw water

\begin{tabular}{llll}
\hline Sample & $\begin{array}{l}\text { Turbidity } \\
(\mathrm{NTU})\end{array}$ & $\mathbf{p H}$ & Alkalinity $\left(\mathrm{mg} \mathrm{L}^{-1} \mathrm{CaCO}_{3}\right)$ \\
\hline$\# 1$ & 105 & 6.90 & 22.0 \\
$\# 2$ & 208 & 7.15 & 24.0 \\
\hline
\end{tabular}


The raw water samples show a tendency to neutral $\mathrm{pH}$ in the water body, with an alkalinity indicating a balance between carbonates and bicarbonates present in raw water $\frac{14}{*}$. However, low alkalinity of water can affect removal efficiency of some synthetic coagulants during the coagulation process ${ }^{15}$. In contrast, water alkalinity does not interfere with efficiency of natural coagulants such as extracts of Moringa oleifera seed ${ }^{16}$.

Results of turbidity removal in water samples are shown in Table 2, which shows behavior of the MSF on treating raw water and clarified water with natural coagulant of Moringa oleifera.

When an ANOVA analysis was applied to the removal efficiency from the filtration rates, turbidity of raw water and use of natural coagulant, a P-value of 0.2392 was obtained, which was higher than 0.05 , indicating that there is no statistically significant difference between the mean turbidity removal when using or not using coagulant, with a $95.0 \%$ confidence level. However, when the ANOVA is calculated with the final turbidity values, a P-value of 0.0219 is obtained, which is less than 0.05 , that is, there is a statistically significant difference between the means of the final concentrations of turbidity in water when natural coagulant is applied. This result is very useful, since it shows that when coagulant is not applied to raw water treated with MSF technology, it is not possible to comply with the turbidity required in the Colombian potable water standard (equal to or less than $2.0 \mathrm{NTU}^{1}$ ) since higher turbidities were obtained to 5.0 NTU. Whereas when coagulant was applied in the treatment with MSF technology, lower turbidities were achieved than the required by the standard.

Figures 1, 2 show the behavior of $\mathrm{pH}$ and water alkalinity, respectively, after the use of coagulant and MSF technology.

In Tables 3, 4, results of the ANOVAS for $\mathrm{pH}$ and Alkalinity are shown, from the values shown in Figures 1 and 2 , respectively.

Table 2. Efficiency of turbidity removal according to the application rate, initial turbidity of the samples and use of natural coagulant

\begin{tabular}{lllll}
\hline Filtration Rate & Raw Water Turbidity (NTU) & Coagulant (M. oleifera) & Final Turbidity (NTU) & Removal (\%) \\
\hline & 105 & With & 1.16 & 99.99 \\
$100 \mathrm{~m}^{3} \mathrm{~m}^{-2} \mathrm{~d}^{-1}$ & 208 & With & 1.20 & 99.40 \\
& 105 & Without & 6.37 & 99.94 \\
& 208 & Without & 5.80 & 97.10 \\
& 105 & With & 1.19 & 99.99 \\
$160 \mathrm{~m}^{3} \mathrm{~m}^{-2} \mathrm{~d}^{-1}$ & 208 & With & 0.94 & 99.53 \\
& 105 & Without & 8.00 & 99.92 \\
& 208 & Without & 17.30 & 91.35 \\
\hline
\end{tabular}

Table 3. ANOVA for the $\mathrm{pH}$ of treated water

\begin{tabular}{llllll}
\hline Source & Sum of Squares & DF & Mean Square & F-Ratio & P-Value \\
\hline Between Groups & 0.12005 & 1 & 0.12005 & 1.2 & 0.3149 \\
Intra Groups & 0.59910 & 6 & 0.09985 & & \\
Total (Correlation) & 0.71915 & 7 & & & \\
\hline
\end{tabular}

Table 4. ANOVA for alkalinity of treated water

\begin{tabular}{llllll}
\hline Source & Sum of Squares & DF & Mean Square & F-ratio & P-Value \\
\hline Between Groups & 0 & 1 & 0 & 0 & 1 \\
Intra Groups & 8 & 6 & 1.33333 & & \\
Total (Correlation) & 8 & 7 & & \\
\hline
\end{tabular}




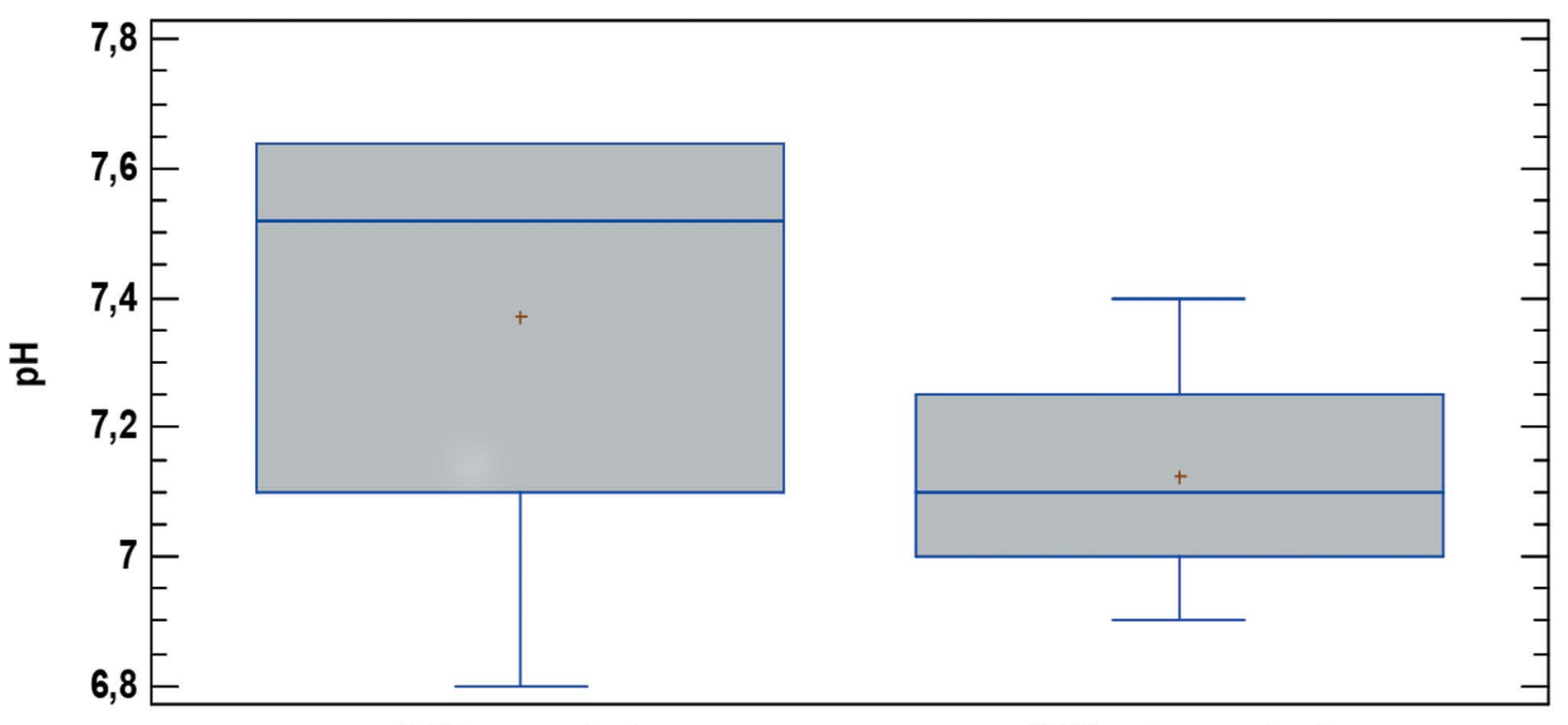

With coagulant

Without coagulant

Figure 1. $\mathrm{pH}$ behavior of water treated with MSF.

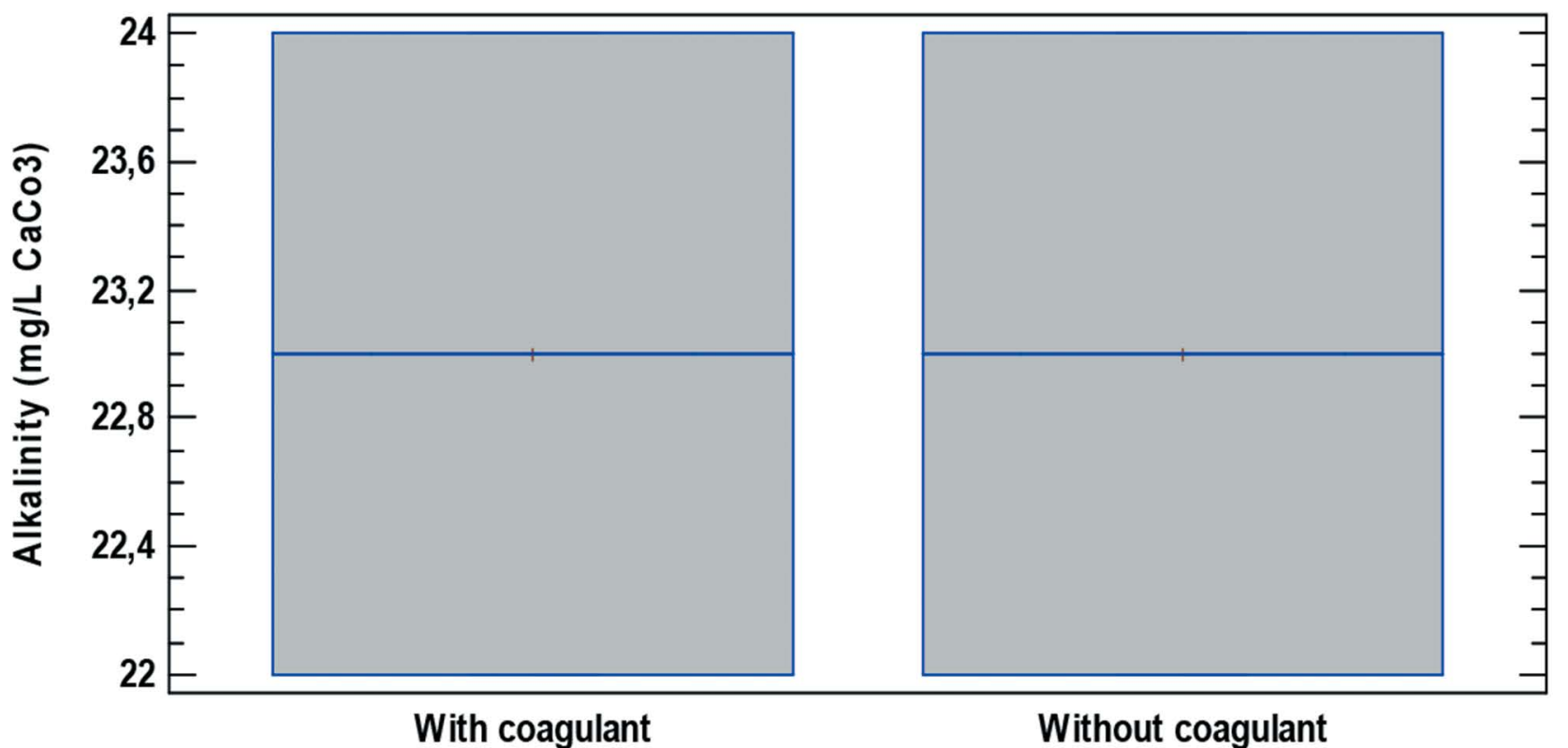

Figure 2. Alkalinity behavior of water treated with MSF.

Since the P-value is greater than or equal to 0.05 , both for $\mathrm{pH}$ and for alkalinity of treated water, there is no statistically significant difference between $\mathrm{pH}$ mean and alkalinity mean, when the coagulant is applied or not, with a $95.0 \%$ confidence level. In other words, there is no statistical evidence that the use of natural coagulant and MSF technology significantly alter the $\mathrm{pH}$ and alkalinity of the water from Sinu River when it is used for the purification of raw water. The same results were reported by ${ }^{9}$ and by ${ }^{16}$ when natural 
coagulant extracts were used in the treatment of raw water from the Sinu River.

\section{Conclusions}

MSF Technology complemented with coagulation with extracts of Moringa oleifera seed allows that, with relatively fast filtration rates, high efficiencies to be achieved in the raw water treatment from the Sinu River. Without the use of natural coagulant, samples treated would not achieve quality standards for turbidity required in the Colombian sanitary standard. The application of MSF technology, with and without natural coagulant, did not significantly affect the initial $\mathrm{pH}$ and alkalinity characteristics of the treated samples.

Filtering in multiple stages is much more efficient than performing only slow filtration in sand. Thick gravel filters are key to reducing water turbidity to acceptable levels for slow filter and MSF fast filter, to achieve near $100 \%$ of removals. The use of MSF is recommended in rural areas of the country where access is difficult and communities have limited economic resources.

\section{Acknowledgement}

The author J.J. Feria thanks Jaime Sánchez and Gustavo Fabra, Sanitary Engineering students from UPB University for their valuable contribution provided on this project.

\section{References}

1. Ministerio de la Protección Social y Ministerio de Ambiente, Vivienda y Desarrollo Territorial. Resolución número 2115, 2007 Jun 22. Bogotá, Colombia; 2007. p. 2-4.

2. Ministerio de Salud y Protección Social, Republica de Colombia. Informe Nacional de Calidad del agua para consumo humano - INCA 2016. Bogotá, D.C.; 2018. p. 1-392.

3. Instituto Nacional de Salud, Dirección en salud Pública. Estado de la vigilancia de la Calidad del Agua para consumo humano 2016. Bogotá, D.C., Colombia; 2017. p. $1-138$.

4. Departamento Nacional de Planeación, Consejo Nacional de Política Económica y Social. Política para el suministro de agua potable y saneamiento básico en la zona rural, Documento Conpes 3810. Bogotá D.C., Colombia; 2014. p. 46.

5. Mushila CN, Ochieng GM, Otieno FAO, Shitote SM, Sitters CW. Hydraulic design to optimize the treatment capacity of Multi-Stage Filtration units. Physics and Chemistry of the Earth, Parts A/B/C. 2016; 92:85-91. https://doi. org/10.1016/j.pce.2015.10.015

6. Wegelin M. Surface water treatment by roughing filters: a design, construction and operation manual. SKAT (Swiss Centre for Development Cooperation in Technology and Management). 1996; 2(96):1-163.

7. Franco M, E Silva G, Paterniani J. Water treatment by multistage filtration system with natural coagulant from Moringa oleifera. Engenharia Agrícola. 2012; 32(5):1-9. https://doi.org/10.1590/S0100-69162012000500018

8. Guzmán L, Villabona A, Tejada C, García R. Reducción de la turbidez del agua usando coagulantes naturales: Una revisión. Revista U.D.C.A Actualidad and Divulgación científica. 2013; 16(1):253-62.

9. Feria JJ, Bermúdez S, Estrada AM. Eficiencia de la semilla Moringa oleífera como coagulante natural para la remoción de la turbidez del río Sinú. Producción + Limpia. 2014; 9(1):9-22.

10. Yin CY. Emerging usage of plant-based coagulants for water and wastewater treatment. Process Biochemistry. 2010; 45(9):1437-44. https://doi.org/10.1016/j. procbio.2010.05.030

11. Centre for Affordable Water and Sanitation Technology. Filtro de arena para técnicos. Calgary, Canadá; 2012. p. 1-56.

12. Feria JJ, Ballut G, Rodriguez J.P. Influence of storage time of moringa oleifera seed on the coagulant activity efficiency for raw water treatment. Indian Journal of Science and Technology. 2018; 11(9):1-4. https://doi.org/10.17485/ ijst/2018/v11i9/121221

13. American Public Health Association-American, Water Works Association, Water Environment Federation. Standard methods for the examination of water and wastewater. 21th Edition. AWWA: Washington, D.C.; 2005.

14. Karanth KR. Groudwater assessment development and management. Tata McGraw Hill Publishing Company Ltd.: New Delhi, India; 1987. p. 1-720.

15. Lozano-Rivas WA, Lozano-Bravo G. Potabilización del Agua: Principios de dise-o, control de procesos y laboratorio. 1st Edition. Editorial Universidad Piloto de Colombia: Bogotá D.C., Colombia; 2015.

16. Rodi-o JP, Feria JJ, Paternina RDJ, Marrugo JL. Sinú River raw water treatment by natural coagulants. Revista Facultad de Ingeniería Universidad de Antioquia. 2015; 76:90-8. 